\title{
Effects of Parametric Variations on Bead Width of Gas Tungsten Arc Welding of AISI 1020 Low Carbon Steel Plate
}

\author{
${ }^{1}$ I.B. Owunna and ${ }^{1 *}$ A.E. Ikpe \\ ${ }^{1}$ Room 142, Department of Mechanical Engineering, Faculty of Engineering, University of Benin, P.M.B. 1154, \\ Benin City, Edo State, Nigeria \\ *Email: ikpeaniekan@gmail.com
}

\begin{abstract}
Variations of welding parameters and their effects on weld bead width of gas Tungsten Arc Weldment of $10 \mathrm{~mm}$ (thickness) AISI 1020 low carbon steel plate was investigated in this paper. Welding experimentation was carried out for Twenty seven (27) runs with three (3) ranges of current $(120 \mathrm{~A}, 150 \mathrm{~A}$ and $190 \mathrm{~A})$, three (3) ranges of voltage $(19 \mathrm{~V}, 21 \mathrm{~V}$ and $25 \mathrm{~V})$ and three (3) ranges of gas flow rate $(13,15$ and $18 \mathrm{~L} / \mathrm{min})$ respectively. Applying the same range of parameters as inputs in Solid Works 2017 version, Finite Element Method (FEM) was employed to predict the weld bead width variations. To avoid wider weld bead width which can contribute to poor weld quality, a condition was established, in which the bead width values from both experimental and FEM prediction must not exceed $1.25 \mathrm{~mm}$. Thermal transient flow simulation was also carried out with Solid Works 2017 version to determine the melting behavior of the material which revealed $1694 \mathrm{~K}$ as the solidus temperature and $1738 \mathrm{~K}$ as the liquidus temperature. It was observed that varying the welding current, arc voltage and the gas flow rate for the welding experimentation and finite element simulation, alternating weld bead widths of close proximity were produced. However, certain sets of parameters used for the welding experimentation met the aforementioned condition $(\leq 1.25 \mathrm{~mm})$ with the following values $1.02 \mathrm{~mm}, 1.05$ $\mathrm{mm}, 1.10 \mathrm{~mm}, 1.07 \mathrm{~mm}, 1.15 \mathrm{~mm}$ and $1.19 \mathrm{~mm}$ while the same combination of parameters in the FEM met the condition with the following FEM predicted values $1.0 \mathrm{~mm}, 1.03 \mathrm{~mm}, 1.08 \mathrm{~mm}, 1.05 \mathrm{~mm}, 1.13$ $\mathrm{mm}$ and $1.15 \mathrm{~mm}$ respectively. These findings are only applicable to AISI 1020 low carbon steel, therefore, melting point of materials should be adequately understood with proper knowledge of welding parameters prior to commencement of welding operation to avoid excessive increase in weld bead width.
\end{abstract}

Indexed Terms- Bead width, Low carbon steel, TIG welding, Welding Temperature, Voltage.

\section{INTRODUCTION}

Due to its malleability, weldability, wide range of applicability and as one of the least expensive steel grades, low carbon steel have been found to be extremely relevant in automotive industries particularly in chassis and body panels of every road-worthy vehicles ranging from saloons and SUVs to heavy duty trucks [1]. Although low carbon steel is prone to corrosion and rust when exposed to the environment in service condition, conventional coating technologies such as galvannealing, zinc electro coating etc. can be used to mitigate against these problems. It exhibits a behavior known as ferromagnetism which makes it easier for steel to be sorted from waste stream, recycled with low energy input and reused in automotive industries [2].

Gas Tungsten Arc Welding (GTAW) also known as Tungsten Inert Gas (TIG) welding process requires the use of non-consumable electrode (EWTh2) to produce an arc suitable for joining two or more metals together, while being shielded by inert gas such as argon or helium to protect the molten weld pool from atmospheric contaminants [3]. GTAW plays a vital role in various metal joining applications such as AISI 1020 low carbon steel which is widely applicable in most industries due to its cold drawn or turned and finished property, high machinability, high strength, high ductility, good weldability etc. 
AISI 1020 low carbon steel is resistant to induction hardening or flame hardening due to its low carbon content and does not readily respond to nitriding due to lack of alloying element [4]. Existing studies have shown that different materials respond differently under GTAW welding parametric variations. Krishnan et al. [5] perform detailed experimental studies to examine the roles of TIG welding parameters such as current, speed and groove angle in the weld bead profiles and joint properties in multi-pass pulsed current gas metal arc welding of $12 \mathrm{~mm}$ thick P91 steel. The result indicated that the joint properties were strongly influenced by the heat input per unit length and the groove angle. A groove angle of $75^{\circ}$ and appropriate choice of process conditions resulted in fairly acceptable bead profile and joint properties.

The effects of welding current and arc voltage on the arc length of Tungsten Inert Gas (TIG) welding of mild steel plate was investigated by Ikpe et al. [6], where four (4) different mild steel plates each of $10 \mathrm{~mm}$ thickness and $100 \mathrm{~mm}$ x $50 \mathrm{~mm}$ (length and width) diameter were joined together through TIG welding process and the welding arc lengths measured consecutively. The results revealed that the higher the welding current and arc voltage, the longer and wider the arc length which is an indication of poor weld quality. Sensitivity analysis carried out by Campbell et al. [7] revealed that welding speed is one of the most important input parameter to be considered when predicting welding bead geometries. The weld bead geometries was predicted using Artificial Neural Network (ANN), followed by welding experimentation using the same input parameters (gas flow rate of $15 \mathrm{~L} / \mathrm{min}$, voltage ranging from 22$26 \mathrm{~V}$ and current of $55 \mathrm{~A}$ ) with alternating shielding gases. While there was correlation in both the ANN predicted and experimental results, the sensitivity analysis revealed that the arc travel speed was the most influential input parameter, with shielding gas being the influential parameter when predicting weld bead geometries.

Sathiya et al. [8] performed an investigation on some weldment characteristics such as bead height, bead width and depth of penetration, as affected by welding parameters like arc-voltage, travel speed, wire feed rate and gas flow rate. The result revealed that weldment characteristics are mainly affected by the bead geometry and penetration. Hussain et al. [9] in an experimental studies investigated the effects of TIG welding process parameters on AA6351 aluminum alloy of 4mm thickness and welding speed of $1800-7200 \mathrm{~mm} / \mathrm{min}$. The result indicated that the tensile strength increased with reducing welding speed.

The effect of TIG welding process parameters on tensile strength and morphology of nickel based alloy plate of 1.2-1.5 mm width, welding current between the range of 55-90A and welding speed between the range of 2100 and $2900 \mathrm{~mm} / \mathrm{min}$ was investigated by Wang et al. [10]. The result indicated an increasing heat input with increasing welding current. Lothongkum et al. [11] in an experimental studies investigated the effect of TIG welding process parameters on 3mm AISI 316L stainless steel plate welded at different welding positions, using argon shielding gas and a combination of argon and nitrogen shielding gas in the percentage volume of $1-4 \%$. The experimental result indicated that increasing percentage of nitrogen in argon shielding gas resulted in decrease of the pulse current, whereas, increasing welding speed brought about increase in the pulse current. Paulraj and Garg [12] studied the effects of Welding parameters on Pitting Behaviour of on Duplex and super duplex stainless steel weldment and lower welding heat input was observed to produce better corrosion properties and vice versa. The effect of Welding parameters on Mechanical properties of GTAW of UNS S31803 and UNS S32750 Weldments also revealed a higher increase in tensile strength of weldment than that of the base metal, decreased impact toughness with increased heat input [13].

However, this study is focused on evaluating the effects of parametric variations on bead width of 10 mm thickness AISI 1020 low carbon steel weldment. With varied welding parameters, TIG welding experimentation will be carried out, followed by thermal transient analysis using Solid Works Finite Element Method (FEM) to predict the corresponding bead width variations. To prevent poor weld quality, result of weld bead width greater than $1.25 \mathrm{~mm}$ in both experimental and FEM prediction will be considered unsuitable for real life application.

\subsection{Governing Equations}

To describe the distribution of temperature field $\mathrm{T}(\mathrm{x}, \mathrm{y}, \mathrm{z}, \mathrm{t})$ within a flat plate, the differential nonlinear equation of thermal conductivity is given by equation 1 [14]; 
$c \rho \frac{\partial T}{\partial t}=\frac{\partial}{\partial x}\left(\lambda_{x} \frac{\partial T}{\partial x}\right)+\frac{\partial}{\partial y}\left(\lambda_{y} \frac{\partial T}{\partial y}\right)+\frac{\partial}{\partial z}\left(\lambda_{z} \frac{\partial T}{\partial z}\right)+Q$

Where $p$ is the density in $\mathrm{kg} / \mathrm{m}^{3}, \lambda$ is the thermal conductivity in $\mathrm{W} /\left(\mathrm{m} .{ }^{\circ} \mathrm{C}\right.$ and $c p$ is the specific heat capacity in $\mathrm{J}\left(\mathrm{m}^{3} .{ }^{\circ} \mathrm{C}\right)$. However, the heat input $(\mathrm{Q})$ is directly related to the arc travel speed and can be calculated using equation 2 [15];

$\mathrm{Q}=\frac{\mathrm{k} * \mathrm{~V} * \mathrm{I} * 60}{\mathrm{~S} * 1000} \mathrm{~kJ} / \mathrm{mm}$

According to Abbasi et al. [16], welding speed is given by equation 3;

Welding speed $=\frac{\text { Travel of Electrode }}{\text { Arc Time }(\mathrm{mm} / \mathrm{min})}$

The total heat input into the electrode takes place through electron condensation, heat and joule heat as expressed in equation 4 [17];

$Q_{\text {total }}=\left(\frac{3}{2} k T / e+V_{\alpha}+\emptyset\right) I+\bar{\rho} \frac{L}{A} I^{2}$

Where $\mathrm{k}$ is Boltzman's constant, $\mathrm{T}$ is the electron temperature entering the electrode, $\mathrm{e}$ is the electron charge, $V_{\alpha}$ is the anode drop voltage, $\varnothing$ is the work function of the electrode, $\bar{\rho}$ is the average resistivity of the electrode, $\mathrm{L}$ is the electrode extension length, and $\mathrm{A}$ is the cross-sectional area of the electrode. However, heat loss resulting from radiation is pronounced when the temperature difference between the welds and the environment is large, and this is given be the standard Stefan-Boltzman criterion expressed in equation 5;

$q_{r}=\varepsilon \sigma\left(T^{4}-T_{\alpha}^{4}\right)$

Where $\varepsilon$ is the heat emissivity and $\sigma$ is the Stefan-Boltzman constant. Applying Fourier's law, the rate of flow of heat energy per unit area through the surface of the workpiece during welding operation is proportional to the negative temperature gradient across its surface, given by equation 6 ;

$q=-k \nabla t$

Where, $k$ is the thermal conductivity and $\mathrm{t}$ is the temperature.

\section{MATERIALS AND METHOD}

$10 \mathrm{~mm}$ thickness of AIS1 1020 low carbon steel was sourced locally and was cut to a dimension of $50 \times 35 \mathrm{~mm}$ (length $\mathrm{x}$ width) each. Emery paper was used to smoothen each of the two specimen to eliminate all possible coatings, corrosion or rust that may have accumulated on the material. The milling of the angle was done using a vertical milling machine. The welding was carried out with the plates properly clamped to avoid misalignment during welding process. Prior to welding, the butt joint (Vgroove) to be welded was cleaned with acetone to eliminate surface contamination and welding was applied on the flat plates. V-groove for each of the two steel plates where chamfered at 30 degrees each after which, TIG welding was used to join the two plates together to form an angle of $60^{\circ}$ with $2 \mathrm{~mm}$ depth. Temperature gradients in the range of $1000 \mathrm{~K}-7500 \mathrm{~K}$ were considered with other parametric variation such as current, voltage, gas flow rate etc. The list of material specification and welding specification used in this study is presented in Table 1. Figure 1 represents the AISI 1020 Low Carbon Steel workpiece welded in this study.

Table 1: Parameters and Welding Specification used for the TIG Welding Process

\begin{tabular}{lll}
\hline S/N & Material Specification & Welding Specification \\
\hline 1 & Welding Type & Tungsten Inert Gas (TIG) \\
2 & Material & AISI 1020 Low Carbon Steel Plate \\
3 & Gas Flow Rate (I/min) & 13,18 and 15 \\
\hline
\end{tabular}




\begin{tabular}{lll}
\hline 4 & Voltage (V) & $19,21,25$ \\
5 & Current (A) & $120,150,190$ \\
6 & Temperature Gradient & $1000,2000,3000,4000,5000,6000,7000$ \\
7 & Material Thickness & $10 \mathrm{~mm}$ \\
8 & Filler Material & ER 70 S-6 \\
9 & Joint Type & Butt Joint (V-groove) \\
10 & Joint Preparation & Abrasive Clean/Acetone Wipe \\
11 & Joint Gap & $2 \mathrm{~mm}$ \\
12 & Welding Current & D.C.E.N (Direct Current Electrode Negative) \\
13 & Pulse Width & 0.8 Seconds \\
14 & Filler Rod Angle & $15^{\circ}$ \\
15 & Welding Torch Angle & $45^{\circ}$ \\
16 & Fixed Frequency & $60 \mathrm{~Hz}$ \\
17 & Torch Type & Pro-torch (TIG Torch) \\
18 & Cup Type/Cup Size & Ceramics/Gas Lens, $7 / 16^{\prime \prime}$ Orifice \\
19 & Tungsten Type & $2 \%$ thoriated \\
20 & Tungsten Size & $3 / 1326$ " Diameter x $25.4 \mathrm{~mm}$ \\
21 & Torch Gas & Argon $(100 \%)$ \\
22 & Heat Input Ratio & $10.75 \mathrm{KJ} / \mathrm{min}$ \\
23 & Weight of Filler Rod & $78.5 \mathrm{Kg} / \mathrm{m}^{2}$ \\
\hline
\end{tabular}

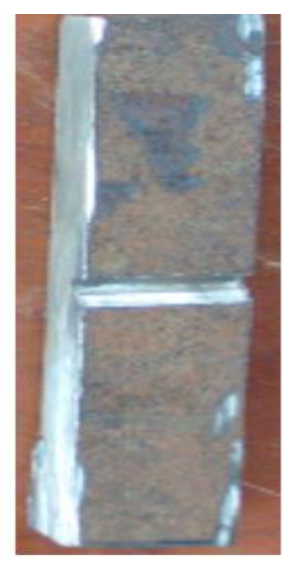

(a) Sample Cut to Dimension

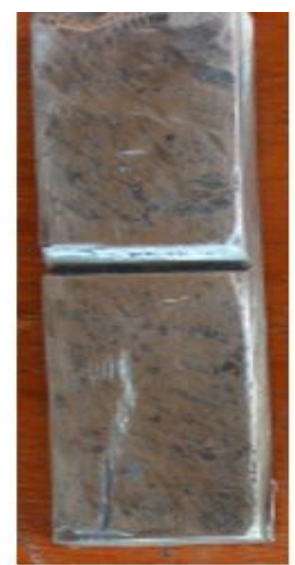

(b) Sample Surface

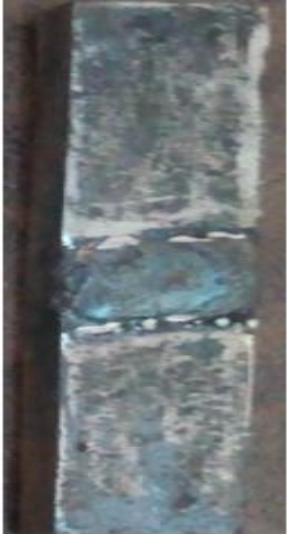

(c) Sample VGroove Welded

Figure 1: AISI 1020 Low Carbon Steel Plate Prepared for Welding

Solid Works (2017 version) was used to model the $10 \mathrm{~mm}$ plate thickness of $50 \mathrm{~mm}$ x $35 \mathrm{~mm}$ (length $\mathrm{x}$ width) dimensions with solid mesh, while Solid Works material selection chart was used to search the AISI low carbon steel and its properties as shown in Table 2. 
Table 2: Mechanical Properties of AISI 1020 Mild Steel plate with Solid Mesh

\begin{tabular}{ll}
\hline Material: AISI 1020 & \multicolumn{1}{c}{ Properties } \\
\hline Model type & Linear Elastic Isotropic \\
Default failure criterion & Max von Mises Stress \\
Yield strength & $351.571 \mathrm{~N} / \mathrm{mm}^{\wedge} 2$ \\
Tensile strength & $420.507 \mathrm{~N} / \mathrm{mm}^{\wedge} 2$ \\
Elastic modulus & $200000 \mathrm{~N} / \mathrm{mm}^{\wedge} 2$ \\
Poisson's ratio & 0.29 \\
Mass density & $7900 \mathrm{~g} / \mathrm{cm}^{\wedge} 3$ \\
Shear modulus & $77000 \mathrm{~N} / \mathrm{mm}^{\wedge} 2$ \\
Melting Point & $1738 \mathrm{~K}$ \\
\hline
\end{tabular}

Prior to commencement of any given welding operation, it is important to consider the melting behaviour of the material to be welded, as this would provide an idea of the amount of heat input required for optimum welding sequence. The above material information (current, voltage and gas flow rate) in Table 1 , was used to simulate the material melting phases for both solidus and liquidus phase in order to understand the transformations taking place within the weldment as a result of parametric variations during the welding process. The thermal analysis was carried out on the $10 \mathrm{~mm}$ steel plate using Solid Works thermal transient flow simulation to compute variations in the weld bead traveling width. The aforementioned parameters in Table 1 were used to carry out thermal transient analysis in Solid Works software to predict the corresponding bead width variations. Since wider bead width may affect the weld quality and aesthetics, constraint of $\leq 1.25 \mathrm{~mm}$ was established in the Solid Works finite element simulation to determine optimal welding parameters.

\section{RESULTS AND DISCUSSION}

Table 3 represents the result obtained from the TIG Welding experimentation and the FEM simulation respectively. Bead with of not greater $1.25 \mathrm{~mm}$ was used as the criteria for selecting optimum welding parameters for AISI 1020 grade of steels. However, welding runs \# 4, 6, 11, 18, 26 and 27 met the criteria, with welding run \#4 having the minimum bead width of all the twenty seven (27) welding runs carried out in this study. Subsequently, the FEM predicted values constituting each welding runs was graphically plotted to examine the relationship between welding temperature ranges, welding parameters and the weld bead width.

Table 3: Experimental and FEM Predicted Bead Width

\begin{tabular}{llllll}
\hline $\begin{array}{l}\text { Welding } \\
\text { Runs \# }\end{array}$ & $\begin{array}{l}\text { Current } \\
(\mathrm{amp})\end{array}$ & Voltage $(\mathrm{V})$ & $\begin{array}{l}\text { Gas Flow } \\
(1 / \mathrm{min})\end{array}$ & $\begin{array}{l}\text { Experimental } \\
\text { Bead Width }(\mathrm{mm})\end{array}$ & $\begin{array}{l}\text { FEM Predicted } \\
\text { Bead Width }(\mathrm{mm})\end{array}$ \\
\hline 1 & 120 & 19 & 13 & 3.891 & 3.792 \\
2 & 120 & 19 & 15 & 4.781 & 4.684 \\
3 & 120 & 19 & 18 & 5.227 & 5.126 \\
$\mathbf{4}$ & $\mathbf{1 2 0}$ & $\mathbf{2 1}$ & $\mathbf{1 3}$ & $\mathbf{1 . 0 2}$ & $\mathbf{1 . 0}$ \\
5 & 120 & 21 & 15 & 5.248 & 5.145 \\
$\mathbf{6}$ & $\mathbf{1 2 0}$ & $\mathbf{2 1}$ & $\mathbf{1 8}$ & $\mathbf{1 . 0 5}$ & $\mathbf{1 . 0 3}$ \\
7 & 120 & 25 & 13 & 5.227 & 5.123 \\
8 & 120 & 25 & 15 & 6.117 & 6.013 \\
9 & 120 & 25 & 18 & 6.912 & 6.718 \\
10 & 150 & 19 & 13 & 4.778 & 4.571 \\
$\mathbf{1 1}$ & $\mathbf{1 5 0}$ & $\mathbf{1 9}$ & $\mathbf{1 5}$ & $\mathbf{1 . 1 0}$ & $\mathbf{1 . 0 8}$ \\
12 & 150 & 19 & 18 & 6.76 & 6.43 \\
\hline
\end{tabular}




\begin{tabular}{llllll}
\hline 13 & 150 & 21 & 13 & 5.43 & 5.22 \\
14 & 150 & 21 & 15 & 6.33 & 6.13 \\
15 & 150 & 21 & 18 & 7.57 & 7.18 \\
16 & 150 & 25 & 13 & 6.12 & 5.98 \\
17 & 150 & 25 & 15 & 7.66 & 7.02 \\
$\mathbf{1 8}$ & $\mathbf{1 5 0}$ & $\mathbf{2 5}$ & $\mathbf{1 8}$ & $\mathbf{1 . 0 7}$ & $\mathbf{1 . 0 5}$ \\
19 & 190 & 19 & 13 & 6.12 & 5.96 \\
20 & 190 & 19 & 15 & 7.45 & 7.10 \\
21 & 190 & 19 & 18 & 7.888 & 7.680 \\
22 & 190 & 21 & 13 & 6.308 & 6.106 \\
23 & 190 & 21 & 15 & 7.708 & 7.521 \\
24 & 190 & 21 & 18 & 9.068 & 8.042 \\
25 & 190 & 25 & 13 & 7.221 & 7.124 \\
$\mathbf{2 6}$ & $\mathbf{1 9 0}$ & $\mathbf{2 5}$ & $\mathbf{1 5}$ & $\mathbf{1 . 1 5}$ & $\mathbf{1 . 1 3}$ \\
$\mathbf{2 7}$ & $\mathbf{1 9 0}$ & $\mathbf{2 5}$ & $\mathbf{1 8}$ & $\mathbf{1 . 1 9}$ & $\mathbf{1 . 1 5}$ \\
\hline
\end{tabular}

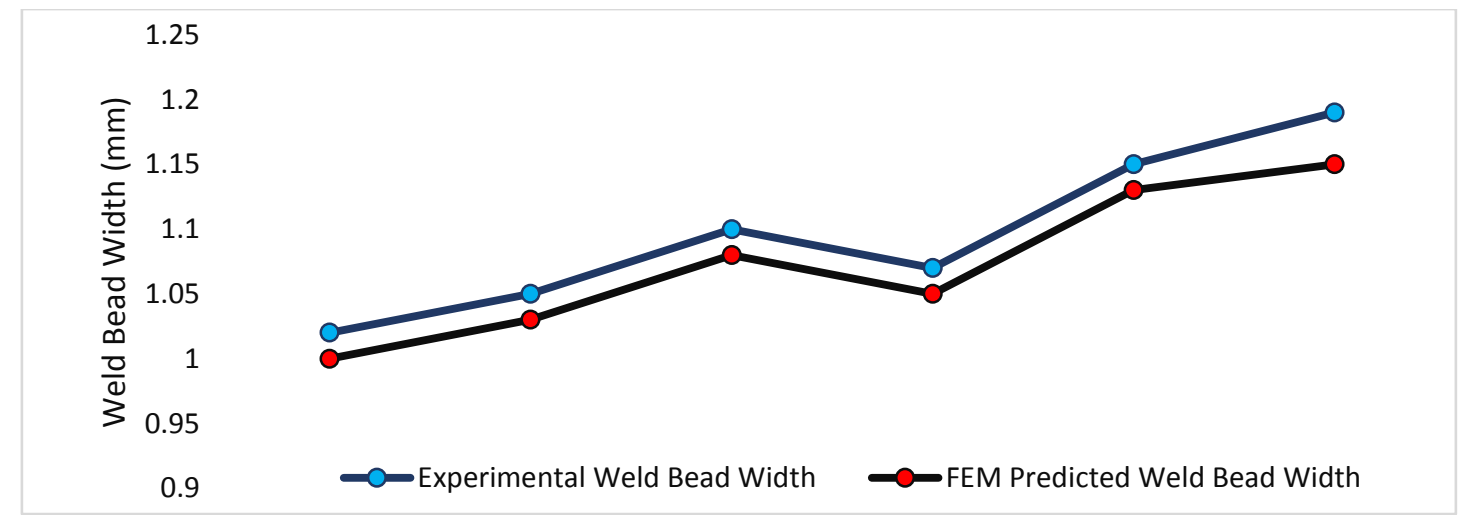

Figure 2: Weld Bead Widths below $1.25 \mathrm{~mm}$ Constrain

Figure 2 is a graphical representation of the weld bead widths below $1.25 \mathrm{~mm}$ constrain specify in this paper. The values plotted are derived from Table 3, representing the weld bead width obtained from the welding experimentation and FEM prediction using Solid Works software. Figure 3 represent melting profile for the AISI 1020 low carbon steel used in the welding simulation process. The temperature distribution profiles obtained from different welding voltage, current and gas flow rate across the two welded metals were observed to be similar and followed the same distribution pattern. Therefore, the temperature distribution profile presented in this section are only shown for one half of the two welded AISI 1020 low carbon steel Plate at varying welding parameters as shown in Figure 4-8. Plot of temperature against thermal conductivity of the welded metal is presented in Figure 9. In addition, Figure 10-15 represent plots of temperature against bead width at varying voltage, current and gas flow rate.

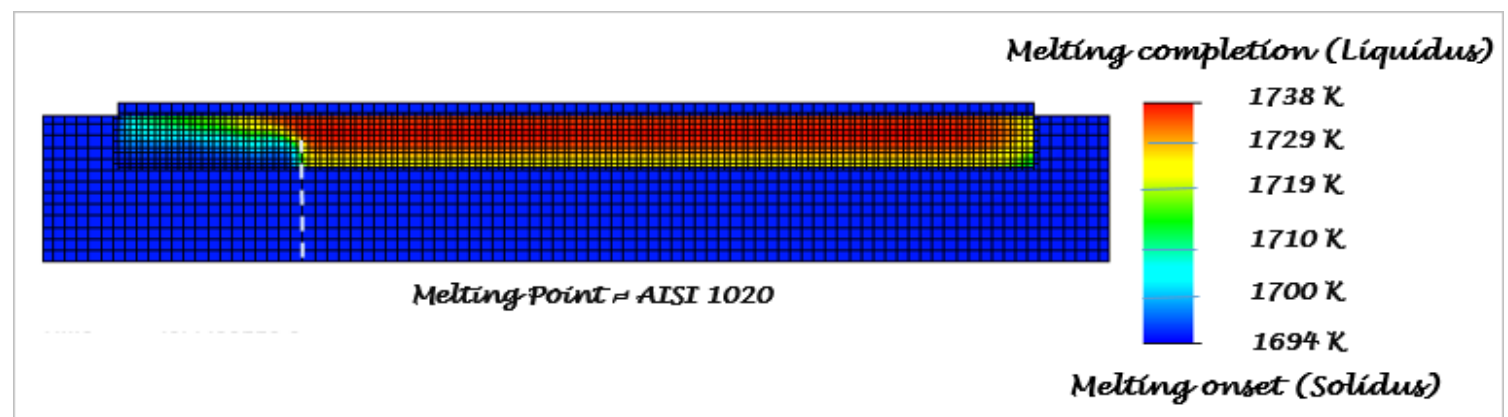

Figure 3: Melting Profile for AISI 1020 Low Carbon Steel 
The melting range for AISI 1020 Low Carbon Steel shown in Figure 3 was used to understand the behaviour of the material during welding and temperature distribution pattern across the metal plate. This was also related to the graphical representation of the welding process for a range of welding temperature variation and their behaviour in response to the welding parameters.

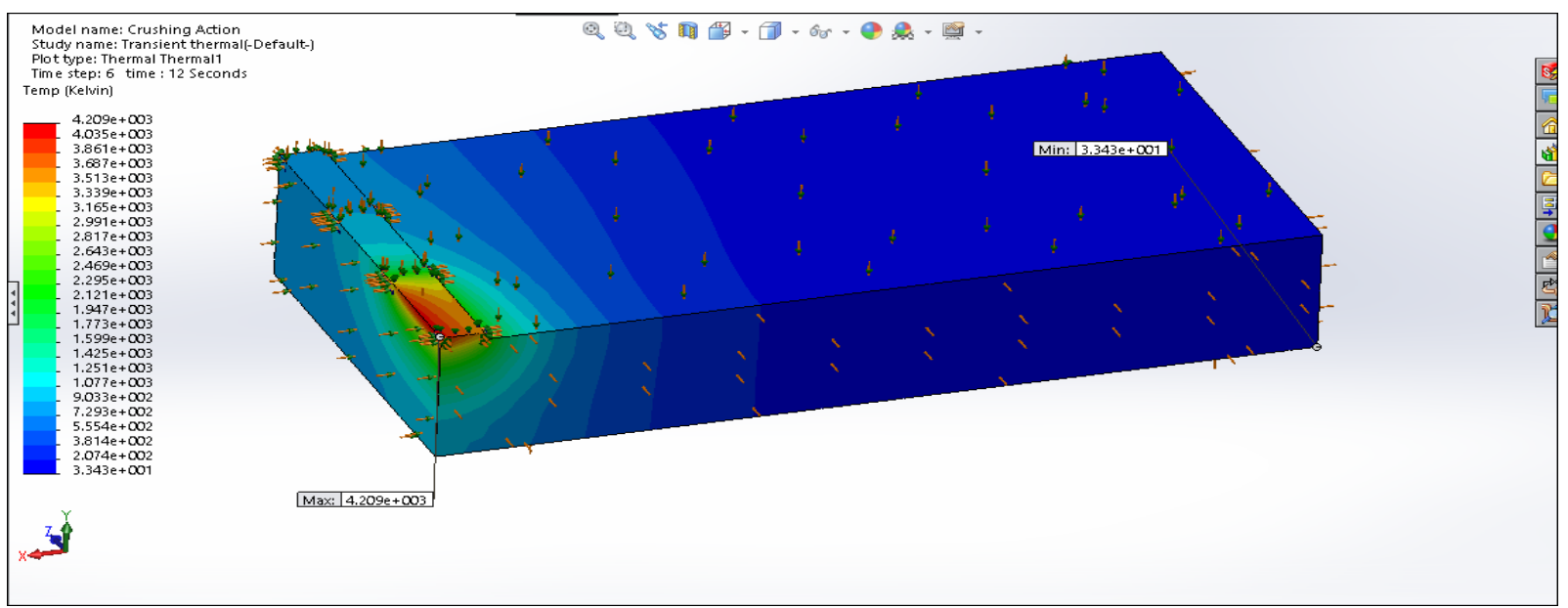

Figure 4: Temperature Distribution Profile at $120 \mathrm{amp}, 21 \mathrm{~V}$ and $13 \mathrm{I} / \mathrm{min}$

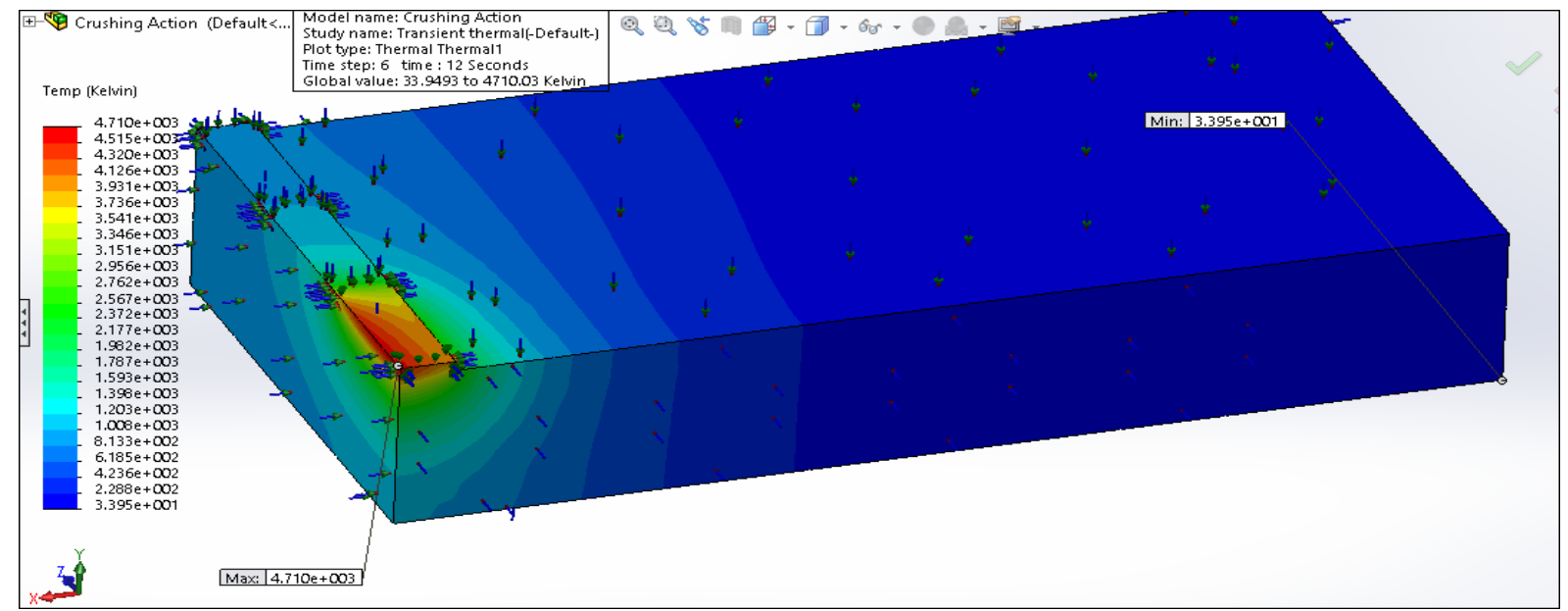

Figure 5: Temperature Distribution Profile at $120 \mathrm{amp}, 21 \mathrm{~V}$ and $18 \mathrm{I} / \mathrm{min}$

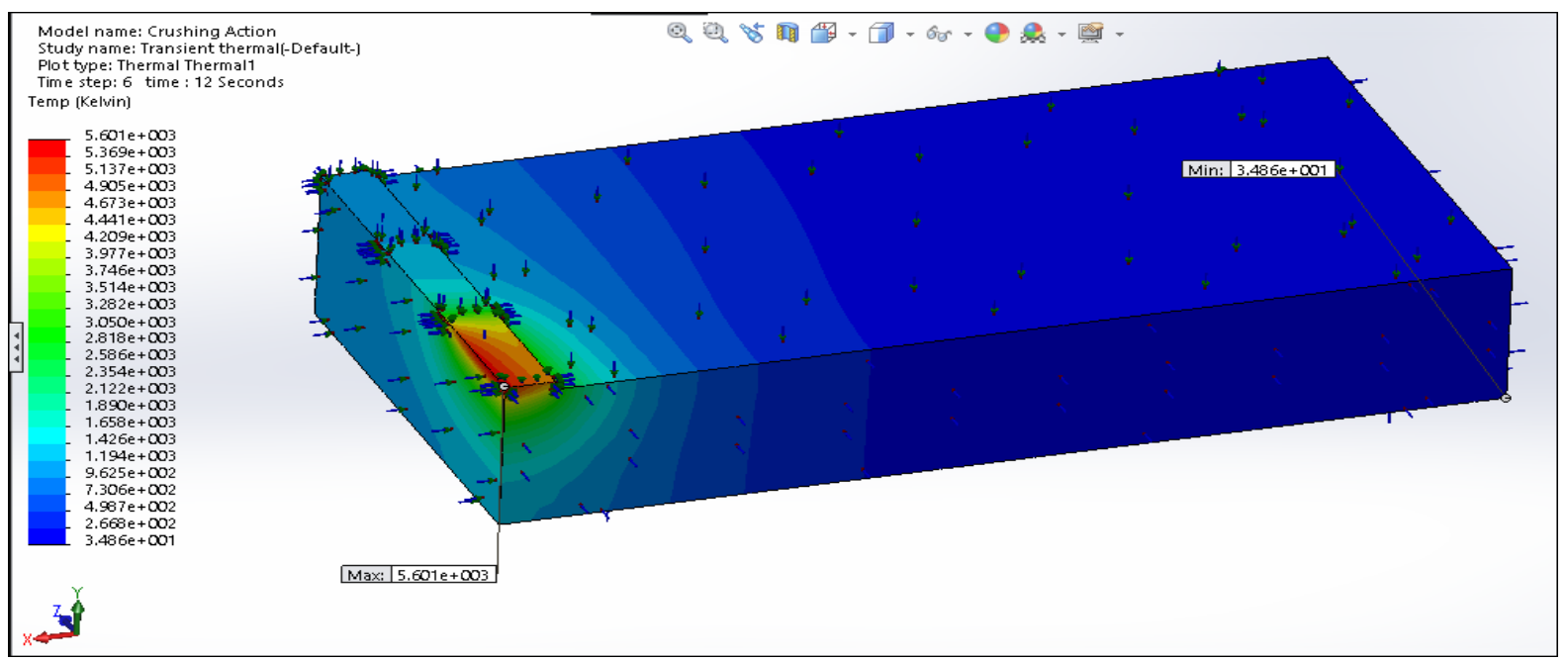

Figure 6: Temperature Distribution Profile at $150 \mathrm{amp}, 25 \mathrm{~V}$ and $18 \mathrm{I} / \mathrm{min}$ 


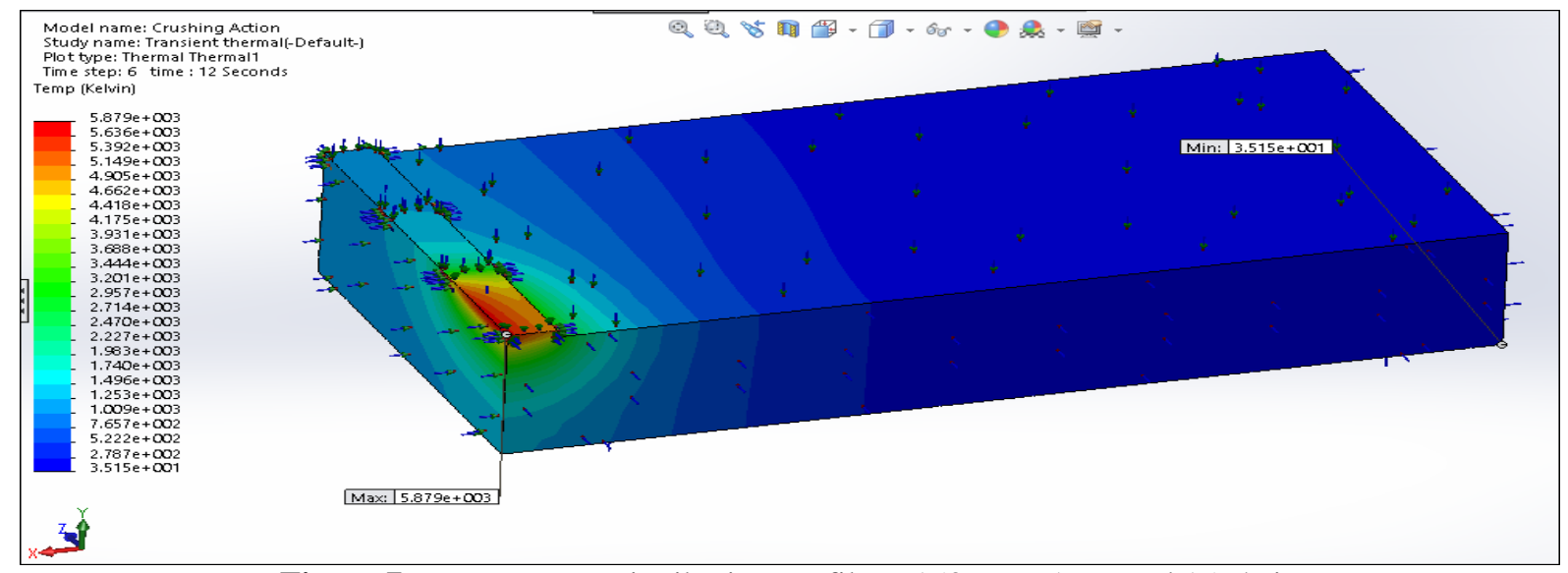

Figure 7: Temperature Distribution Profile at $150 \mathrm{amp}, 19 \mathrm{~V}$ and $15 \mathrm{I} / \mathrm{min}$

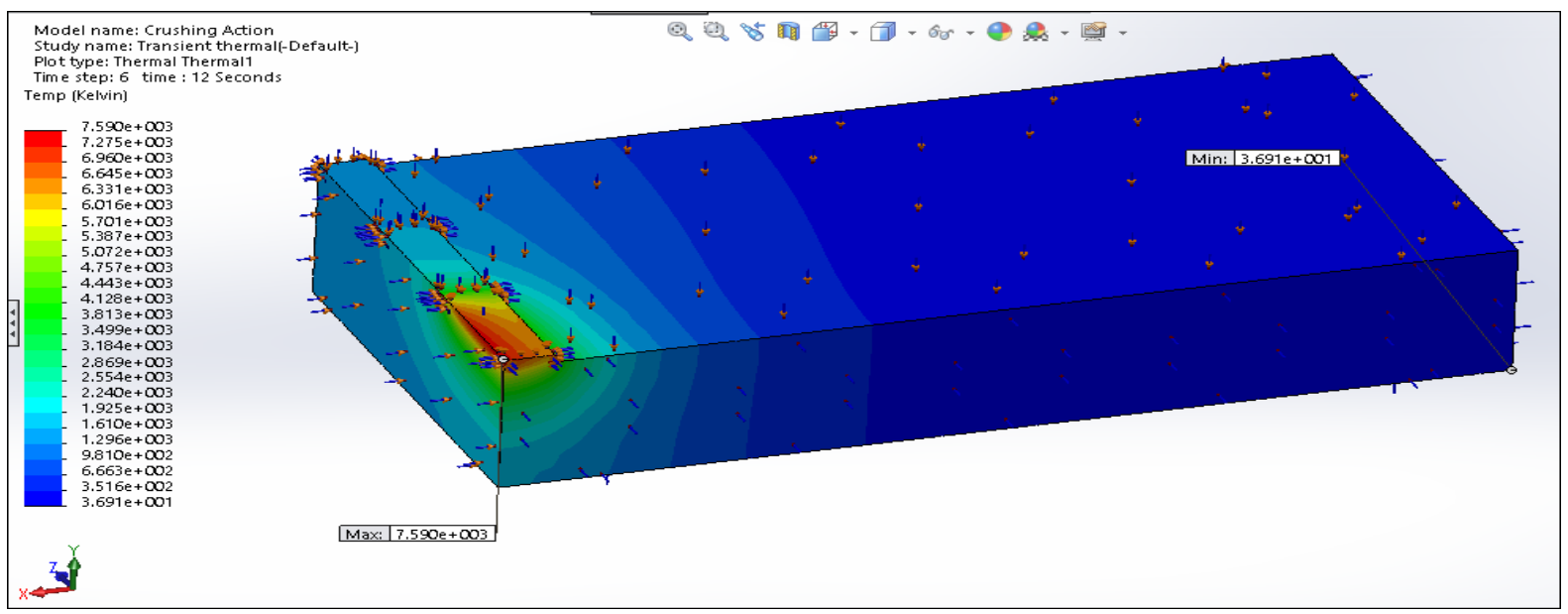

Figure 8: Temperature Distribution Profile at $190 \mathrm{amp}, 25 \mathrm{~V}$ and $15 \mathrm{I} / \mathrm{min}$

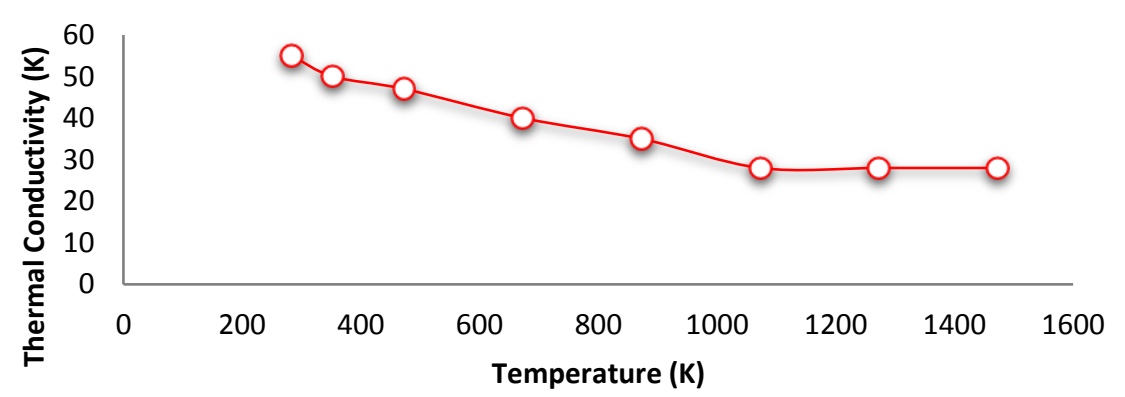

Figure 9: Plot of Temperature against Thermal Conductivity of the Welded Metal 


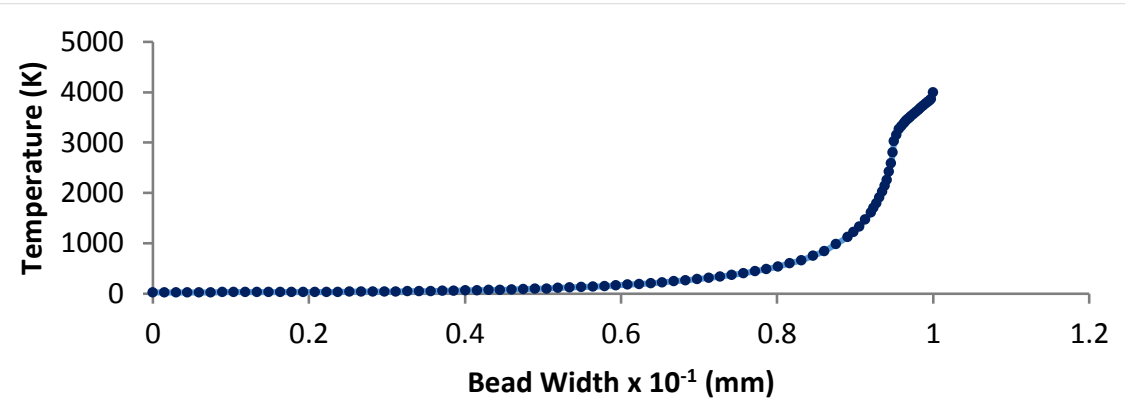

Figure 10: Plot of Temperature Vs Bead Width @ $120 \mathrm{amp}, 21 \mathrm{~V}$ and $13 \mathrm{I} / \mathrm{min}$

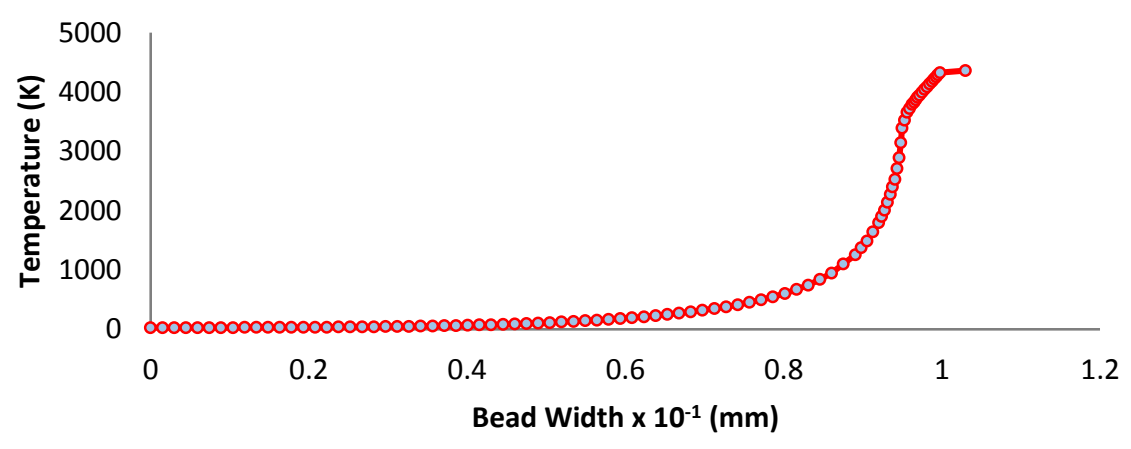

Figure 11: Plot of Temperature Vs Bead Width @ $120 \mathrm{amp}, 21 \mathrm{~V}$ and $18 \mathrm{I} / \mathrm{min}$

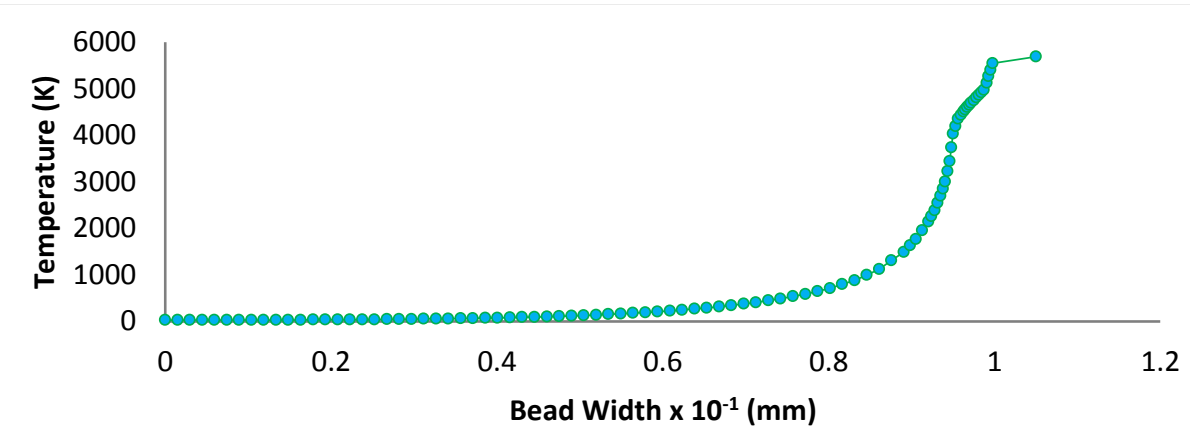

Figure 12: Plot of Temperature Vs Bead Width @ $150 \mathrm{amp}, 25 \mathrm{~V}$ and $18 \mathrm{I} / \mathrm{min}$

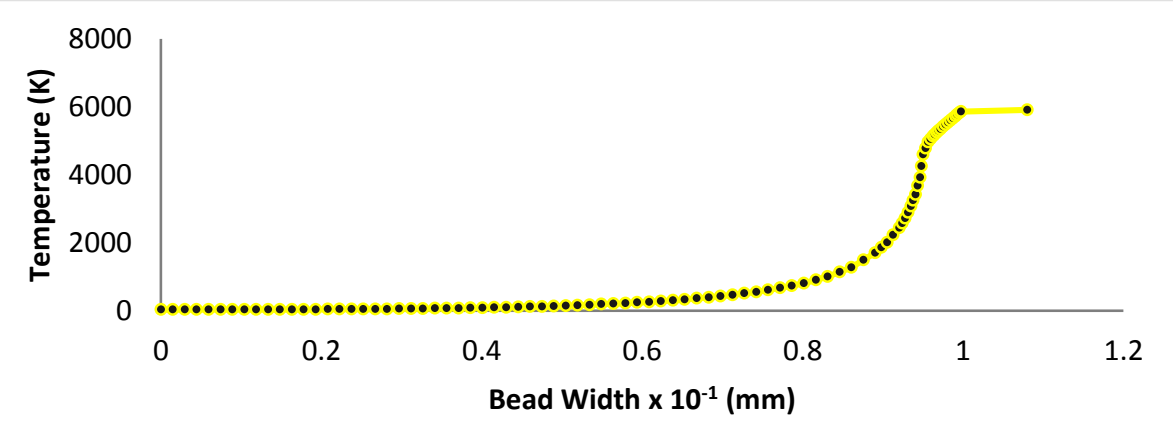

Figure 13: Plot of Temperature Vs Bead Width @ 150 amp, $19 \mathrm{~V}$ and $15 \mathrm{I} / \mathrm{min}$ 


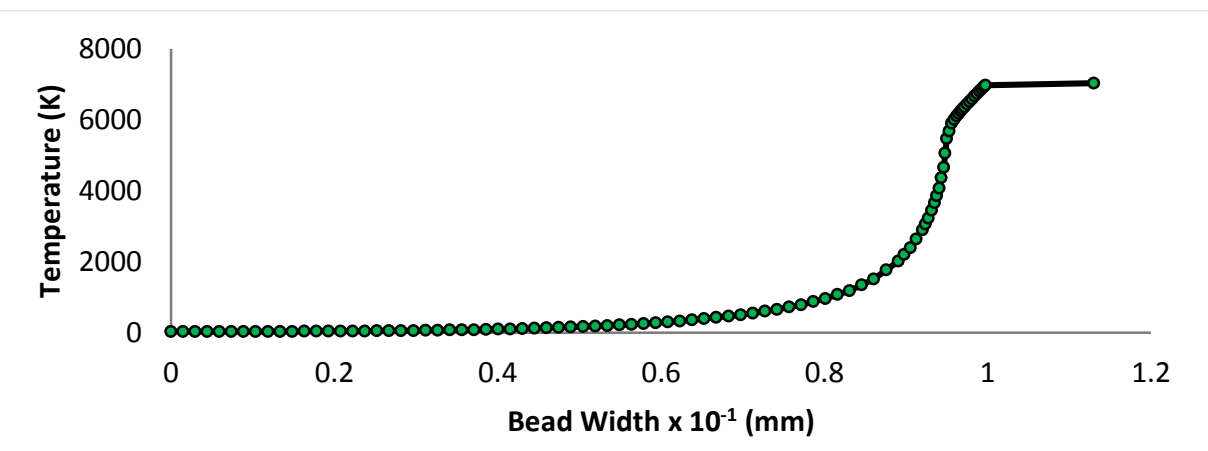

Figure 14: Plot of Temperature Vs Bead Width @ 190 amp, 25 V and 15 I/min

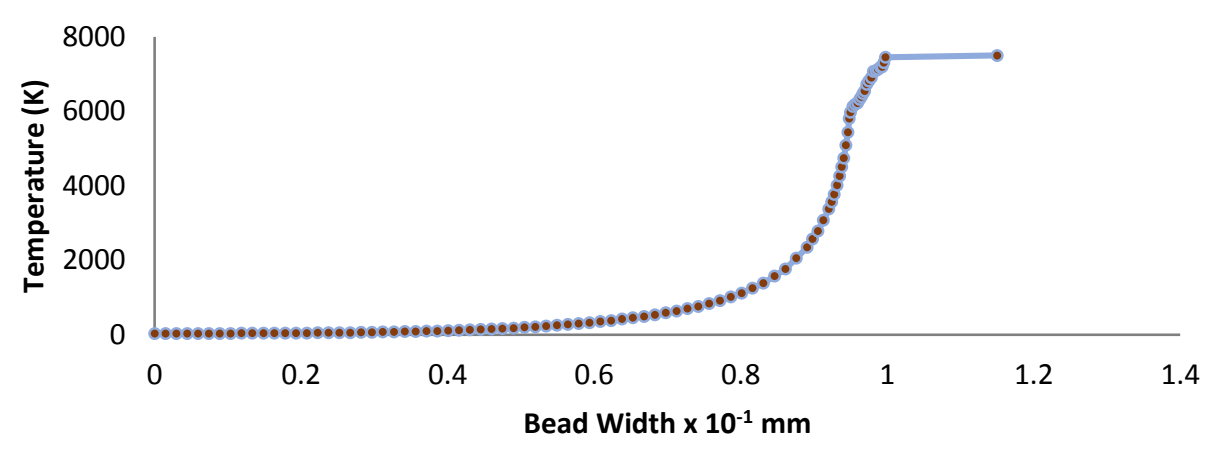

Figure 15: Plot of Temperature Vs Bead Width @ $190 \mathrm{amp}, 25 \mathrm{~V}$ and $18 \mathrm{I} / \mathrm{min}$

Solidus phase which quantifies the highest temperature at which solid metals begin to melt, but not completely melted and liquidus phase is the temperature at which a metal is completely melted. In other words, the metal is partly solid and partly liquid at temperatures between the solidus phase and liquidus phase whereas, the span of temperature from the point at which the metal begins to liquefy to the point at which the entire metal becomes molten liquid is known as melting range which for the AISI 1020 low carbon steel used in this study was determined from Figure 3. The temperature profiles in Figure 4-8 represent transient thermal analysis on the welded plate at different temperatures and parametric variations in terms of current, voltage and gas flow rate for each profile.

The colour distribution on the profiles indicate the intensity of heat transfer across the plate and red colour which represent the area with the highest welding temperature reveals the point of contact between the plate and the arc electrode. However, as the heat distribution increases the colour chart spreads widely from the Heat Affected Zone (HAZ) across the entire plate with different colour views. As shown in Figure 9, thermal conductivity of the AISI 1020 low carbon steel decreased with increase in temperature. This is because, the thermal conductivity of any material is dependent on two major conditions namely; the motion of free electrons and molecular vibrations. For metals, the thermal conductivity basically is a function of the motion free electrons. Therefore, as the welding temperature increases the molecular vibrations within the material also increases which in turn causes the mean free path of molecules within the material to decrease, thereby, obstructing the flow of free electrons and thus, causing reduction in the thermal conductivity of the material. Moreover, due to lattice distortion in metals higher temperature makes it difficult for electrons to flow, thereby reducing thermal conductivity of the metal. This is contrary to non-metals where there are no free (or quasi-free) electrons, as such, only the molecular vibrations are responsible for heat conduction, thus, the thermal conductivity increases with increase in temperature. This is so for pure metals, but the presence of impurities in metal may reverse the trend.

The thermal conductivity of a metal is affected by several factors including temperature, atomic structure, phase change grain size, chemical composition etc. Relating the direction of the weld traveling bead, to the melting profile for AISI 1020 low carbon steel in Figure 3, it can be observed that the 
material initially remained in its solid state until the welding heat began to propagate gradually. This can be observed in Figure 10 where the curve remained constant at zero temperature $\left(0^{\circ} \mathrm{C}\right)$ but began to travel upwards from $0.43 \mathrm{~mm}$ to $0.92 \mathrm{~mm}$ near solidus temperature at $1610 \mathrm{k}$, and finally terminated at $1 \mathrm{~mm}$ at 3,900 k with bead travel width of $0.08 \mathrm{~mm}$. In Figure 11, the curve remained constant at zero temperature $\left(0^{\circ} \mathrm{C}\right)$ but began to travel upwards from $0.40 \mathrm{~mm}$ to $0.91 \mathrm{~mm}$ near solidus temperature at $1644 \mathrm{k}$, and finally terminated at $1.03 \mathrm{~mm}$ at $4,360 \mathrm{k}$ with bead travel width of $0.12 \mathrm{~mm}$. As shown in Figure 12, the curve remained constant at zero temperature $\left(0^{\circ} \mathrm{C}\right)$ but began to travel upwards from 0.35 $\mathrm{mm}$ to $0.89 \mathrm{~mm}$ near solidus temperature at $1630 \mathrm{k}$, and finally terminated at $1.05 \mathrm{~mm}$ at $5,687 \mathrm{k}$ with bead travel width of $0.16 \mathrm{~mm}$. The curve remained constant at zero temperature $\left(0^{\circ} \mathrm{C}\right)$ but began to travel upwards from $0.37 \mathrm{~mm}$ to $0.89 \mathrm{~mm}$ slightly above solidus temperature at $1700 \mathrm{k}$, and finally terminated at $1.08 \mathrm{~mm}$ at $6000 \mathrm{k}$ as shown Figure 13 with bead travel width of $0.19 \mathrm{~mm}$. In Figure 14, the curve remained constant at zero temperature $\left(0^{\circ} \mathrm{C}\right)$ but began to travel upwards from $0.35 \mathrm{~mm}$ to $0.86 \mathrm{~mm}$ near solidus temperature at $1517 \mathrm{k}$, and finally terminated at $1.13 \mathrm{~mm}$ at $7,033 \mathrm{k}$ with bead travel width of $0.27 \mathrm{~mm}$. As represented in Figure 15, the curve remained constant at zero temperature $\left(0^{\circ} \mathrm{C}\right)$ but began to travel upwards from $0.38 \mathrm{~mm}$ to $0.84 \mathrm{~mm}$ near solidus temperature at $1574 \mathrm{k}$, and finally terminated at $1.15 \mathrm{~mm}$ at $7502 \mathrm{k}$ with bead travel width of $0.31 \mathrm{~mm}$.

\section{CONCLUSIONS}

A Welding parameters depending on their input can have optimal or negative effects on welded metals, as each material have different melting point and therefore respond differently to these parameters such as current which is a function of the heat input (welding temperature), voltage which is a function of the arc length and gas flow rate which protects the weldment against atmospheric contamination. Determining the melting range of AISI 1020 low carbon steel plate in this study, it was observed that the bead geometry in terms of the bead width travel rate changed at varying current, voltage and gas flowrate. The bead width increased as the temperature increased due to heat input from the current while the voltage at variable rates $(21 \mathrm{~V}, 25 \mathrm{~V}$ and $19 \mathrm{~V})$ also contributed to the changes on the bead width. This is the reason why constant current power supply is required for manual welding operation such as TIG welding, as they maintain a relatively constant current even as the voltage varies, knowing too well that increasing both parameters may produce an increasingly flat and wider weld beads when the material gradually exceed its liquidus temperature as shown in Figure 10 and 11. Furthermore, excessively high welding temperature and voltage (shown in Figure 12-15) may result in a wider bead that would subject the weldment to thermal stress cracking, increased undercut, increased side wall fusion defects and difficulty in slag removal while amperage set too low may result in a narrow and erratic beads that would affect fusion of the metal plates, whereas, gas flowrate exceeding $20 \mathrm{I} / \mathrm{min}$ in AISI 1020 may create turbulent gas flow that can attract outside air into the weld area and cause porosity.

\section{Nomenclature:}

A

ANN

AISI

$\mathrm{cm}$

$c p$

DCEN

$\varepsilon$

FEM

GTAW

HAZ

$\mathrm{K}$
Ampere, Cross-sectional Area of Electrode

Artificial Neural Network

American Iron and Steel Institute

Centimetre

Specific Heat Capacity

Direct Current Electrode Negative

Heat Emissivity

Finite Element Method

Gas Tungsten Arc Welding

Heat Affected Zone

Kelvin 


$\begin{array}{ll}\mathrm{k} & \text { Boltzman's constant } \\ \mathrm{KJ} & \text { Kilojoules } \\ \mathrm{L} & \text { Electrode Extension Length } \\ \mathrm{mm} & \text { millimetre } \\ p & \text { Density } \\ \bar{\rho} & \text { Average Resistivity of Electrode } \\ \mathrm{Q} & \text { Heat Input } \\ \varnothing & \text { Work Function of Electrode } \\ \mathrm{SUVs} & \text { Sport Utility Vehicles } \\ \mathrm{t} & \text { temperature } \\ \lambda & \text { Thermal conductivity } \\ \sigma & \text { Stefan-Boltzman constant } \\ @ & \text { at } \\ \mathrm{TIG} & \text { Tungsten Inert Gas } \\ \mathrm{UNS} & \text { Unified Numbering System } \\ \mathrm{V} & \text { Volts } \\ V_{\alpha} & \text { Anode drop voltage }\end{array}$

\section{REFERENCES}

[1] Yaakob, K.I., Ishak, M. and Idris, S.R., "The Effect of Pulse Welding Parameters on Weld Geometry of Boron Steel Using Low Power Fibre Laser", Journal of Mechanical Engineering and Sciences, 11(3), 2895-2905, 2017.

[2] Janke, D., Savov, L., Weddige, H. J. and Schulz, E., "Scrap-Based Steel Production and Recycling of Steel", Material Technology, 34(6), 387-399, 2000.

[3] Srirangan, A. K. and Paulraj, S., "Multi-response Optimization of Process Parameters for TIG Welding of Incoloy 800HT by Taguchi Grey Relational Analysis", Engineering Science and Technology, International Journal, 19(2), 811-817, 2015.

[4] Cardona, D. M., Wongsa-Ngam, J., Jimenez, H. and Langdon, T. G., "Effects on Hardness and Microstructure of AISI 1020 Low-carbon Steel Processed by High Pressure Torsion", Journal of Materials Research and Technology, 6(4), 355-360, 2017.

[5] Krishnan, S., Kulkarni, D. V. and De, A., "Multipass Pulsed Current Gas Metal Arc Welding of P91 Steel", Journal of Science and Technology of Welding and Joining, 21(3), 171-177, 2016.

[6] Ikpe, A. E., Owunna, I. and Ememobong, I., "Effects of Arc Voltage and Welding Current on the Arc Length of Tungsten Inert Gas Welding (TIG)", International Journal of Engineering Technologies-IJET, 3 (4), 213-221, 2017.

[7] Campbell, S. W., Galloway, A. M. and Mcpherson, N. A., "artificial neural network prediction of weld geometry performed using GMAW with alternating shielding gases", Welding Journal, 91(6), 174S-181S, 2012.

[8] Sathiya, P. Aravindan, S. Ajith, P.M. Arivazhagan, B. and Noorul H. A., "Microstructural characteristics on bead on plate welding of AISI $904 \mathrm{~L}$ super austenitic stainless steel using Gas metal arc welding process", International Journal of Engineering, Science and Technology 2(6), 189-199, 2010.

[9] Hussain, A. K., Lateef, A., Javed, M. and Pramesh, T., "Influence of Welding Speed on Tensile Strength of Welded Joint in TIG Welding Process", International Journal of applied Engineering Research, Dindigul 1(3) 518-527, 2010.

[10] Wang, Q., Sun, D., Na, Y., Zhou, Y., Han, X. and Wang, J., "Effects of TIG Welding Parameters on Morphology and Mechanical Properties of Welded Joint of Ni-base Supper Alloy", Procedia Engineering 10, 37-41, 2011. 
[11] Lothongkum, G., Viyanit, E. and Bhandhubanyong, P., "Study on the Effect of Pulsed TIG Welding Parameters on Delta-ferrite Content, Shape Factor and Bead Quality in Orbital Welding of AISI 316L Stainless Steel Plate”, Journal of Materials Processing Technology 110(2), 233-238, 2011.

[12] Paulraj, P. and Garg, R., "Effect of Welding parameters on Pitting Behaviour of DSS and Super DSS Weldments", Engineering Science and Technology and International Journal 19, 1076-1083, 2016.

[13] Paulraj, P. and Garg, R., "Effect of Welding parameters on Mechanical properties of GTAW of UNS S31803 and UNS S32750 Weldments", Manufacturing Review 2(29), 1-9, 2015.

[14] Mi, G., Li, C., Gao, Z., Zhao, D., and Niu, J., "Finite Element Analysis of Welding Residual Stress of Aluminium Plates Under Different Butt Joint Parameters", Engineering Review, 34(3), 161-166, 2014.

[15] Lincoln Electric, "Mild Steel-BOC World of Welding", AU: IPRM 2007: Section 8: consumables, 330-372, 2007.

[16] Abbasi, K., Alam, S. and Khan, M., "An Experimental Study on the Effect of MIG Welding parameters on the Weld-Bead Shape Characteristics", Engineering Science and Technology: An International Journal 2(4), 599-602, 2012.

[17] Kim, Y. S. and Eagar, T. W., "Analysis of Metal Transfer in Gas Metal Arc Welding", Welding Research Supplement", 269-278, 1993. 